\title{
Conjunctival Carcinoma pT1 TNM Finding v8
}

National Cancer Institute

\section{Source}

National Cancer Institute. Conjunctival Carcinoma pT1 TNM Finding v8. NCI Thesaurus. Code C140539.

Conjunctival carcinoma with tumor measuring $5 \mathrm{~mm}$ or less in greatest dimension and invading through the conjunctival basement membrane without invasion of adjacent structures. (from AJCC 8th Ed.) 